\title{
SCHOOL MEDICAL INSPECTIONS, THEIR VALUE AND LIMITATIONS
}

\author{
BY \\ I. GORDON, M.D., M.R.C.P., D.P.H. \\ Deputy Medical Officer of Health, Ilford, Essex
}

(Received April 22, 1947)

This investigation on 2,500 schoolchildren was started in 1938 and finished in 1946, with a gap of four and a half years due to war service. It began as an endeavour to answer the question, "How healthy are our schoolchildren?" and ends as an attempt to estimate the value and limitations of routine school medical inspections, and to note how results may be made valuable or of lesser worth by the interest of the examiner, so giving but a partial answer to the original query. The children were of both sexes and aged from 5 to 14, and they attended the elementary schools of Ilford, Essex, a "dormitory" type municipal borough in outer London, with a school population of approximately 17,000. Vital statistics show that Ilford is one of the healthier parts of the country, the relevant figures for 1940 (chosen as most examinations were done between 1939 and 1941), with those of England and Wales in brackets for comparison, being: crude* death rate per $1,000,10 \cdot 3$ (14.3); infant mortality, $31 \cdot 5$ (55) per 1,000 live births; tuberculosis death rate per $100,000,48 \cdot 1(68 \cdot 7)$ (Annual Report of the Medical Officer of Health, Ilford, 1940). It has repeatedly been asked how far figures such as these reflect the true morbidity of a community, and perhaps investigations such as this one will help to provide an answer. The sample is not strictly representative of the child community, as the more severely ill and defective children either do not go to school at all or attend special establishments. Furthermore, at most sessions there are some absentees who are temporarily kept at home by ill health. They will include many of the children suffering from such disorders as pulmonary catarrh and asthma, which will thus go unrecorded. This is, accordingly, a somewhat optimistic review of the child community. Very few parents $\dagger$ refuse to allow their children to be seen by the school doctor; it is unknown how these absences weight the results. Some children also attend schools in other districts, or non-maintained schools in Ilford, and are thus not recorded.

* Standardized rates for individual administrative areas are unfortunately not available in the Registrar-General's Statistical Review for 1940, nor are they present in the Annual Report of the Medical Officer of Health.

$\dagger 0.67 \%$ in 1,940 instances. 
Ilford is within easy reach of the London teaching hospitals, including the Hospital for Sick Children, Great Ormond Street, and so a large proportion of the defective children will have had the opportunity of the best specialist advice, which is sure to have been reflected in the recorded diagnosis.

\section{METHOD OF INSPECTION}

Each child is given a small printed slip of paper to take home. On it the parent records in the very briefest outline particulars of the child's medieal history. These particulars are later transferred to the school medical card just before the actual examination. When the child is inspected the parent or guardian, according to inclination or opportunity, is or is not present. The examination of a five-year-old child with no parent present can be of very little value, and tends to vitiate the conclusions of any investigation, but it is only fair to add that most parents of the younger children make an effort to attend and are grateful for advice. On an average each child is allotted five minutes for a complete examination, and in view of the shortage of medical man-power it is difficult to see how this period can be increased. During this time the doctor examines the child according to the routine he has developed, talks to the mother, perhaps writes a note for specialist advice, and personally records results on the medical card. For this investigation the results had also to be entered separately under various headings in a special notebook, by which time the next mother and child would be waiting and some of the data almost forgotten. It will be realized that only a considerable degree of enthusiasm can give any reliability to the results, and records taken from the usual run of medical cards will be of little value.

Usually the examination is conducted in the teachers' common room, the teaching staff allotting the best available room, which is not always suitable; for school accommodation, like all building accommodation, has not been able to catch up yet with the demand. The most modern Ilford schools, built just before the late war, have special medical inspection rooms, but even so the schools are often so overcrowded that they may be used for other purposes.

The children came from twenty-two schools in all parts of the borough. Each child examined in this survey appears only once; colds and acute bronchitis were ignored, and so it is in no sense, like the Medical Research Council Special Report on "Epidemics in Schools" (1938), an epidemiological survey or follow-up. Finally, it should be pointed out that procedures vary considerably from one local education authority to another.

\section{DEFECTS RECORDED}

With the exception of figures relating to tonsillectomies and circumcisions, referable to groups of 1,000 children, and data on cryptorchidism, referable only to boys of the number specified, all figures are based on findings in 2,500 personally recorded consecutive routine medical inspections. As there are about 150 defects, they have been divided up into groups, to make reading easier. It is realized that the ensuing classification, like most classifications, has serious defects. Some conditions could easily be placed in other groups; certain conditions, such as affections of the ear and tuberculosis, should have been further subdivided. Furthermore, some conditions listed are merely signs or symptoms which are not.necessarily specific, for example, head-rocking and exophthalmos, but opportunity was lacking for complete diagnosis. The incidence of some defects will of course vary somewhat according to the individual doctor's interests and opinions with respect to adequate criteria for diagnosis. The incidence of defects found on inspection will 
be considered first, then a list of the conditions from which the child had already recovered, and then some minor findings.

\section{Dental Disease}

Dental disease is beyond doubt the commonest defect. As inspections are carried out by the school dentist, no special data on the subject were collected for this survey. In 1940, of 9,984 children inspected in Ilford schools, $56 \%$ were recommended for dental treatment (Annual Report of the M.O.H., Ilford, 1940).

\section{Minor Traditional Surgery (Tonsillectomies and Circumcisions)}

Tonsillectomy had been carried out in 235 of 1,000 children aged 5 to 9 years and 374 of 1,000 children aged 10 to 14 years, that is, about $31 \%$ of all children from 5 to 14 years. The social and geographical status of children has much to do with the incidence of tonsillectomies. Glover and Wilson (1932) state it to have been $14 \%$ in England and Wales and $33 \%$ in London among children in public elementary schools. Paton (1943) found it to be $57 \%$ in a girls' public school. In the Medical Research Council Survey (1938) "Epidemics in Schools", the incidence was $52.5 \%$ among boys in 1930 and $43.3 \%$ among girls. It increased regularly until 1934, the incidence then being $58.2 \%$ in boys and $50.1 \%$ in girls. In spite of considerable changes of opinion as to the value of the operation, the local hospitals still have lengthy waiting lists that will require a year or more to clear. It is not often remarked how badly the operation is sometimes done, holes in the soft palate and distortion of the pillars being none too rare. Much of the tonsil may be left behind, or it grows again.

Out of 1,000 consecutive tonsillectomies, there had been complete removal of 576; in 301 a small slice of tonsil remained; in 101, large portions of tonsil were still present; and in 22 cases complete tonsils were visible, though the parent was quite definite that the operation had been done. Many of these operations were done in other parts of the country, and, as Paton (1943) reports similar findings, they cannot be considered as peculiar to Ilford. Hitherto tilting against this wholesale tonsil and adenoids removal has had little effect. It has been done before on high authority, inter alia in "Epidemics in Schools" (1938), and by Glover and Wilson (1932), and with no success whatsoever.

Circumcision had been performed in 305 out of 1,000 male children, only a small proportion of these for ritual reasons.

It should be noted that figures for tonsillectomy and circumcision refer to the years 1939-41.

\section{Alimentary Tract}

$$
\begin{aligned}
& \begin{array}{lllll}
\text { Constipation } & . & \ldots & \ldots & 6
\end{array}
\end{aligned}
$$

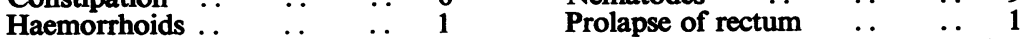$$
\text { Nematodes } \quad \ldots \quad \ldots \quad \ldots \quad 9
$$

The feature here is the obvious under-estimation of these defects, no doubt because the history has not been sufficiently probed. It would be useful to find out the true number of those who are constipated, if only to impose a limitation on 
the quantity of purgatives used. As Cram (1943) has pointed out, the incidence of threadworms is very high ( $41 \%$ in Washington) or, if still better methods of investigation used, $100 \%$ (in Amsterdam, Schüffner et al., 1943). The $0.36 \%$ noted here may well be a gross understatement, since it is not based on special physical examination or leading question.

Allergy

$\begin{array}{lrrrllllr}\text { Angio-neurotic oedema } & \ldots & 1 & \text { Hay fever } & \ldots & \ldots & \ldots & 6 \\ \text { Asthma } & . . & \ldots & 27 & \text { Migraine } & \ldots & \ldots & \ldots & 24 \\ \text { Besnier's prurigo } & \ldots & \ldots & 12 & \text { Urticaria } & \ldots & \ldots & \ldots & 2\end{array}$

It is not often realized how common migraine is among children. It includes cases that were once known as acidosis. Biliousness, perhaps pain in the abdomen, recurrent headache, with almost certainly a history of headache in the mother, are the main features.

\section{Developmental Errors}

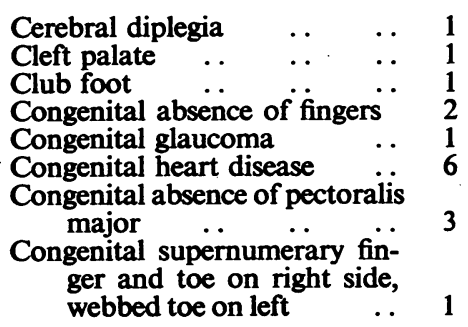

$\begin{array}{lllll}\text { Projecting ears } & . . & . . & . . & 2 \\ \text { Hypospadias } & . . & . . & . . & 1 \\ \text { Infantilism } & . . & . . & . . & 2 \\ \text { Oxycephaly } & . . & . . & . . & 1 \\ \text { Torticollis } & . & . . & . . & 1 \\ \text { Uvula, bifid } & . & . & . & 6 \\ \begin{array}{l}\text { Uvula, elongated } \\ \text { Webbed fingers }\end{array} & . . & . . & . . & 1 \\ \begin{array}{l}\text { Webbed toes } \\ \text { Curly toes }\end{array} & . . & . . & . . & 1 \\ \end{array}$

The interest here lies in the variety of developmental errors, although each one is rare, represented by mostly one case each. The cases of curly toes and projecting ears included in the list were conspicuous as such. No doubt minor examples are far more common.

Ear, Nose, and Throat

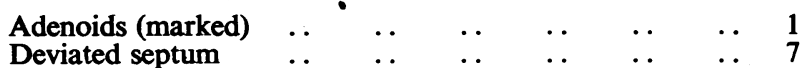

$$
\begin{aligned}
& \begin{array}{lllllll}
\text { Ear disease (unclassified) } & \ldots & . & \ldots & \ldots & \ldots & 66
\end{array}
\end{aligned}
$$

For two reasons, no attempt has been made to record incidence of average tonsil and adenoid disease: (i) about $30 \%$ have had these structures removed; (ii) I am disinclined to label any case of tonsillar trouble on one examination, and always have cases re-inspected some months later, when it is often found that conditions have considerably changed. It is regretted that the auroscope was not used in every case as a routine; doubtless it would have demonstrated a much higher proportion of ear disease (Wilkins, 1940). 
Educationally Subnormal*

Under the Education Act of 1944 the term includes not only those formerly called mentally defective but also the dull or backward. During the major part of the years included in this survey there was no provision for special classes in Ilford for these children, who, unless severely backward, attended ordinary schools and should have been found there. It is obvious that the majority were missed at routine examinations, for about $250(10 \%)$ would be expected ("Special Educational Treatment ", 1946). Routine medical examinations identified 6 only; but this is not surprising, because the school teacher rather than the doctor usually takes the first step to pick out these defectives when the annual return of handicapped pupils is called for by the medical officer of health. Some are also discovered by the Maternity and Child Welfare services and transferred from them. Eye

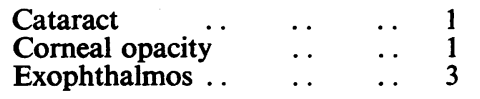

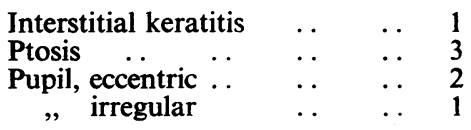

In addition to these twelve cases listed, 195 children had errors of refraction. No tests for colour vision were carried out.

\section{Miscellaneous}

$\begin{array}{llll}\text { Acholuric jaundice } & \ldots & \ldots & 1\end{array}$

$\begin{array}{llll}\text { Adenitis (cervical) } & \ldots & \ldots & 1 \\ & \ldots & . & 3\end{array}$

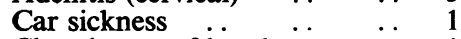

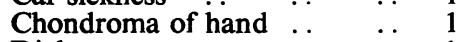

Diabetes

$\begin{array}{lllll}\text { Extrasystoles } & \ldots & \ldots & \ldots & 1 \\ \text { Train sickness } & \ldots & \ldots & \ldots & 1 \\ \text { Ganglion wrist } & \ldots & \ldots & \ldots & 1 \\ \text { Hammer toes } & \ldots & \ldots & \ldots & 1 \\ \text { Hip disease } & \ldots & \ldots & \ldots & 1 \\ \text { Raynaud's disease } & \ldots & \ldots & 1\end{array}$

Neurological Disorders

$\begin{array}{lllllllll}\text { Erb's palsy } & \ldots & \ldots & \ldots & 2 & \text { Pyknolepsy } \ldots & \ldots & \ldots & 1 \\ \text { Epilepsy } & \ldots & \ldots & \ldots & 2 & \text { Wry neck, spasmodic } & \ldots & \ldots & 2\end{array}$

Severe cases of this category are not found at school, and parents who do not wish to report rare fits of epilepsy do not do so.

\section{Nutrition}

$\begin{array}{llllrlllll}\text { Obesity } & \ldots & \ldots & \ldots & 25 & \text { Undernutrition } \dagger & & & & \\ \text { Rickets } & \ldots & \ldots & \ldots & 1 & \text { (marked) } & \ldots & \ldots & \ldots & 11\end{array}$

The classification of children in the four deficiency groups, A, B, C, and D, has not been recorded in view of the gross lack of concordant diagnosis. The 11 cases of nutrition disorders here mentioned were sufficiently striking to be noted.

* Pupils who, by reason of limited ability or other conditions resulting in educational retardation, require some specialized form of education wholly or partly in substitution for the education normally given in ordinary schools. A decision is arrived at after examination by a specially qualified school medical officer, the examination involving an IQ test and consideration of the teacher's report.

$\dagger$ Children who were markedly underweight, and presented a picture of lassitude with dull texture of skin. 


\section{Postural and Skeletal Defects}

\begin{tabular}{|c|c|c|}
\hline$t$ chest & & \\
\hline Gen & & \\
\hline i's sulcus & & \\
\hline $\begin{array}{l}\text { Kyphosis } \\
\text { Lordosis }\end{array}$ & & \\
\hline Pes valgo-planus & & \\
\hline
\end{tabular}

$$
\begin{array}{llllr}
\text { Pigeon chest } & \ldots & \ldots & \ldots & 8 \\
\text { Scoliosis .. } & \ldots & \ldots & \ldots & 2 \\
\text { Slack posture } & . & \ldots & \ldots & 10 \\
\text { Sternum depressed } & \ldots & \ldots & 5
\end{array}
$$

Only the most severe cases have been noted. If the list included all minor cases of slack posture, knock knee, symptomless flat feet, pes valgus, and hallux valgus, the numbers would undoubtedly be very many times greater, so great, in fact, that the problem of treatment would no longer be a medical one. At least some slack posture comes very definitely in the psychosomatic category, and is often a reflection of the child's attitude towards life. The infant of 5 years of age, especially if female and friendly, tends to loll and might mistakenly be marked down as a case of slack posture. Wilkins (1941) gives the percentage of those with pes valgus in the 5 to 10 years age group as $38 \%$, in the 11 to 15 years group as $46 \%$. Hallux valgus rises from $5 \%$ to $52 \%$ from the 5 -year-olds to the 11 to 15 years age group. If it be true that these minor deviations from the normal are the precursors of extensive adult deformities, we are presented with a massive problem in therapy and a smaller, but not less important one, in the education of school medical officers.

Psychological and Behaviour Disorders

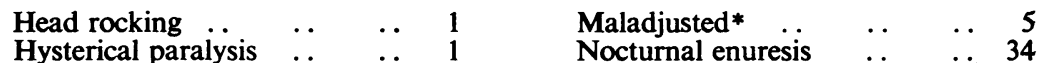

Enuresis $(1.3 \%)$ is probably under-estimated, for in an ad hoc investigation (Gordon, 1942) using a leading question, the incidence was found to be $7 \%$ in 200 cases. Mảladjusted children are missed, as about 25 should have been found ("Special Education Treatment ", 1946) in place of 5, again no doubt due to lack of time for special questioning. There had been no complaint of night terrors, although in a special investigation of 200 children the incidence was found to be $9 \%$ (Gordon, 1942). Mothers often state that their children (usually healthy) suffer from "nerves". How to investigate this problem is suggested later.

\section{Pulmonary Catarrh}

- The 45 cases recorded include chronic bronchitis, bronchiectasis, etc., difficult to diagnose in school, but with the common feature of several seasonal recurrences. As people have at times short memories the incidence recorded will be less in summer than in winter.

\section{Rheumatism Manifestations}

$\begin{array}{lllrllll}\text { Chorea (history) } & \ldots & \ldots & 10 & \text { Rheumatic fever (history) } & \ldots & 4 \\ \text { Rheumatism } & \ldots & \ldots & \ldots & 1 & \text { Rheumatic heart disease } & \ldots & 6\end{array}$

* Pupils who show some evidence of emotional instability or psychological disturbance and require special educational treatment in order to effect their personal, social, or educational : readjustment. 
It is obvious that the small numbers cited above would not keep the Borough Rheumatism Clinic as busy as it is. Perhaps this is because cases of "growing pains ", functional cardiac murmurs, and habit spasm, here rigorously excluded, also find their way to the specialist in large numbers. Moreover, severe cases would not be at school. Functional cardiac murmurs have not been recorded in this survey.

During 1940, 169 Ilford children paid on an average two visits each to the Rheumatism Clinic. Acute rheumatism is a locally notifiable disease, under the Ilford (Acute Rheumatism) Regulations, the average annual notifications of the pre-evacuation years of 1936-9 being 31. Evidently, therefore, the disease is numerically a minor problem in this part of Greater London.

Sex Organs

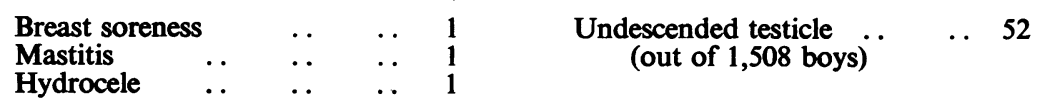

Needless to say, the testicle must be palpated and if not in the scrotum an attempt must be made to push it there. In cold weather the testicle is drawn up. Time and time again perfectly normal cases have, therefore, been labelled " undescended testicle " because the examiner has ignored the importance of palpation.

Skin

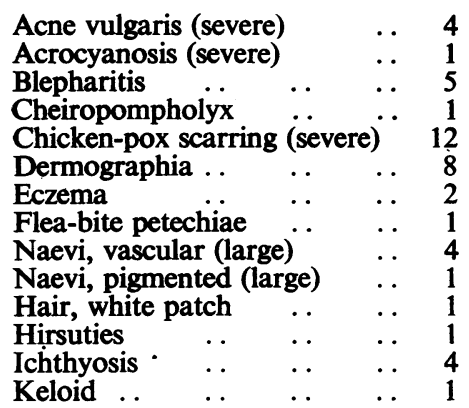

\begin{tabular}{|c|c|c|}
\hline Pruritus ani & & \\
\hline $\begin{array}{l}\text { Pruritus anı } \\
\text { Pruritus, generalized }\end{array}$ & .. & \\
\hline Pruritus vulvae & $\cdots$ & * \\
\hline Psoriasis & .. & $\because$ \\
\hline Ringworm, scalp & & $\because$ \\
\hline Scabies .. & & \\
\hline Streptococcal fissures & (ear) & \\
\hline Tinea cruris & .. & \\
\hline Vitiligo :. & 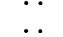 & \\
\hline Warts (multiple) & & \\
\hline $\begin{array}{l}\text { Dermatitis medic } \\
\text { (a) poultice }\end{array}$ & & \\
\hline
\end{tabular}

The custom indicated by the last item is valueless to all except the manufacturers, and should be discontinued. Care should also be taken in applying poultices.

For several reasons this series cannot be considered in any way a complete picture of skin disease in schoolchildren. Many skin conditions vary from time to time, such as acrocyanosis (seasonal); others, such as scabies, are temporary and then forgotten. Some are exceedingly common when mild, such as acne vulgaris, naevi, lichen urticatus, common warts, and so have not been recorded. Impetigo contagiosa does not appear, as cases would mostly have been removed from school already; likewise, children infected by lice, so a record of the few found would be misleading. The absence of cases of tinea pedis, and the occurrence of one case of tinea cruris, can probably be put down to lack of time and facilities for examination. 
Speech Defects 37

These defects are usually easily recognized. The percentage $(1.6 \%)$ is not far from that suggested in "Special Educational Treatment" (1946), i.e. $1.5 \%$ to $3.0 \%$, which of course includes several defects not found at school.

Tongue

$\begin{array}{llllllllll}\text { Geographical tongue } & . . & \ldots & 20 & & \text { Enlarged papillae } & \ldots & \ldots & 1 \\ \text { Glossitis } & . . & \ldots & \ldots & 3 & \text { Tongue-tie } & . . & \ldots & \ldots & 2\end{array}$

Veins

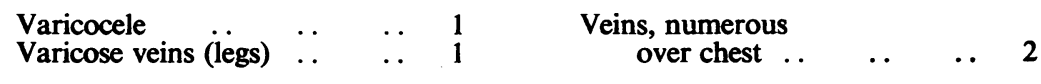

Major Medical Conditions (Excluding Minor Childhood Exanthemata) from the history

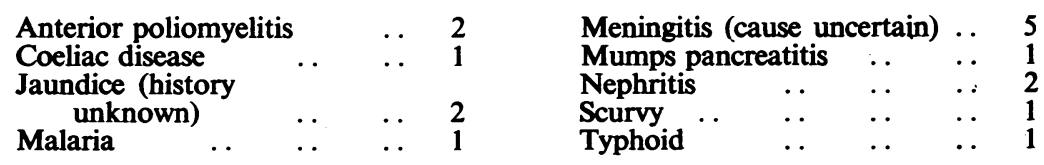

\section{Major Surgery}

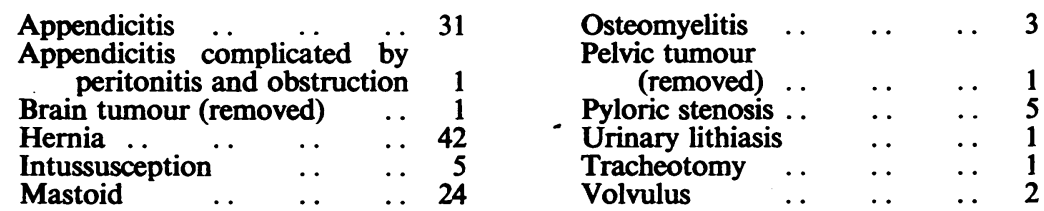

Evidence for these was obtained both from the history and the presence of scars.

\section{Trauma}

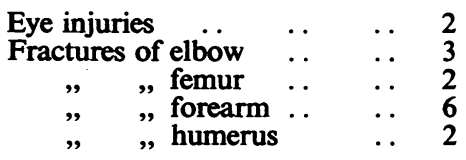

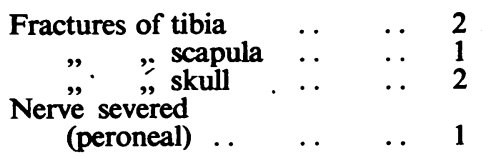

\section{Tuberculosis}

Mainly history of glandular forms, but, with the following exception, not subdivided: 18

$\begin{array}{llllll}\text { Tuberculosis of spine (history) } & \ldots & \ldots & \ldots & \ldots & 2\end{array}$

\section{Some Minor Conditions}

$\begin{array}{lllllllll}\text { Habit spasms } & \ldots & \ldots & \ldots & \ldots & \ldots & \ldots & 14\end{array}$

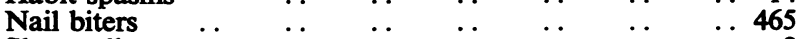

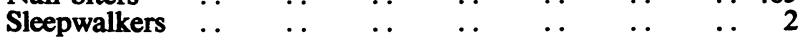




\section{Open Air School}

The 2,500 examinations which formed the basis of the preceding figures do not include those of the children in the borough open air school. The school serves the whole borough, and the 2,500 examinations already discussed cover only one-seventh of the school population of Ilford. The 76 cases in attendance at the school, as listed by diagnosis below, refer, therefore, to a total school population of about 17,000 .

\begin{tabular}{|c|c|c|}
\hline Achondroplasia & & \\
\hline Asthma & & . \\
\hline Bronchitis & & \\
\hline Congenital disloc & n, hip & 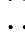 \\
\hline Congenital diseas & eart & $\cdot$ \\
\hline Debility & . & . \\
\hline Hemiplegia & . & • \\
\hline Little's disease & .. & $\bullet$ \\
\hline
\end{tabular}

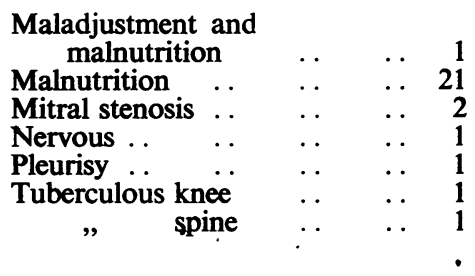

\section{Discussion}

Routine school medical inspection raises two questions of fundamental importance: (i) What conditions does it disclose? (ii) What conditions does it fail to discover?

\section{Conditions Disclosed by Routine Medical Inspections}

The cynic may reply, "Conditions already recognized by the parent." However, there are exceptions to this statement. Parents rarely make any fuss about postural defects, and often do not notice that a boy has an undescended testicle or varicocele. Skin conditions such as scabies or the rash caused by rubbing in medicated oils often present themselves for diagnosis. In Ilford most people can afford a doctor for their children, and it is but a bus-ride to the large teaching hospitals. Accordingly, few major conditions remain for an initial diagnosis at school. In less fortunate parts of the country conditions are doubtless otherwise.

Be this as it may, there is one sense in which medical inspections do in fact disclose conditions which would otherwise remain concealed. Statistics of the incidence of school-age complaints which are neither notifiable nor appear on death certificates are hard to come by, and school inspection is one of the main ways of obtaining them. To assess their true worth we have to recognize any survey undertaken through public health authorities as excluding the so-called public schools and other private schools, institutions dealing with special defects, and individuals temporarily absent at the time of inspection. With due regard to these limitations, this paper draws attention to the following facts worthy of comment in this connexion: the existence of $4.7 \%$ with a history of major operations; $30 \%$ circumcised and about $30 \%$ with tonsillectomies; the prevalence of migraine (24 cases); the infrequency of rheumatic heart disease (6 cases); the incidence of mild congenital defects (for example, 3 cases of absence of the pectoralis major); the prevalence of dermatitis medicamentosa. 


\section{Conditions not Disclosed by Routine Medical Inspections}

The limitations to diagnosis caused by putting a doctor in a room not always intended for medical inspection and by giving him five minutes per child, perhaps without the parent, must be apparent to all. Nothing not immediately apparent to the hand, eye, and ear will be noticed, and, unless the doctor is especially aware and trained, not even those. On the other hand, a complete overhaul as practised in some American clinics, by a team of specialists, is impossible even if it were desirable. To suggest a satisfactory policy it is necessary to find out what conditions the present method misses or under-estimates, a difficult problem as comparable data are not always available. Some of these statements must, therefore, be considered impressions from general experience, and are so described in the context: (1) psychological and behaviour problems that would be disclosed by an adequate history helped by judicious leading questions, as indicated by absence of cases of maladjusted children, educationally subnormal children, nocturnal enuretics, children complaining of night terrors; (2) cases that might cause some embarrassment in discussion, which in their severer manifestations might be characterized as disorders, such as masturbation and menstrual difficulties; (3) the absence of anaemia is also noticeable, and, partly at least, attributable to unwillingness to diagnose anaemia on the ground of colour alone.

The ensuing four headings deal with impressions rather than proven facts: (4) alimentary disorders, depending mainly on a good history, have also been underestimated; colic, constipation, biliousness, unless causing trouble just about the time of the examination, were forgotten; (5) conditions that require meticulous inspection, such as tinea cruris, tinea pedis, threadworms, haemorrhoids, are mostly missed; (6) seasonal conditions, such as hay fever, acrocyanosis, chilblains, bronchitis, tend to be ignored if the inspection is carried out in the season in which they do not occur; (7) in recording histories, omissions and inaccuracies are manifold. The mother's story, for example, of " pneumonia ", " congestion of the lungs ", " bronchial catarrh ", makes any statistical record of a history of pneumonia of little value:

\section{ADdITIONAL IMPRESSIONS}

Is any Harm done by Routine Inspections?

As in other branches of medicine, the injudicious doctor may implant a neurosis by unnecessarily emphasizing some harmless or mild condition. The chances of this are probably more frequent in schools, as that vast border country between normal and abnormal is so much larger when dealing with supposedly normal groups, and the subjects are at a most suggestible age. It is for the doctor to decide when plumpness becomes obesity, thinness malnutrition, when a stoop is abnormal, when flat feet require treatment, when a few spots become acne, or growing pains rheumatism. Individual doctors vary greatly in their estimation of where this 
border-line lies, and usually have not been so instructed, because medical education concerns itself mostly with the distinctly pathological, and not the normal. All physicians know by now the dangers of implanting a cardiac neurosis in cases with a functional murmur, and in the case of most schoolchildren a specialist is readily available for reference. One point to be remembered is that the five-year-old who has just started school shows a multitude of temporary disorders, large tonsils, cervical adenitis, bronchitis, "nerves ", slackness of posture, " catarrh", all of which turn out to be evanescent when a special re-examination is arranged six or twelve months later, when the child is already habituated both psychologically and immunologically to the school environment.

\section{What Good can be done by the Routine Medical Inspection?}

The critic who declares that routine inspections do more harm than good is easily answered when he states that they focus attention on minor or non-existent complaints, for in this modern and not always well-educated society that reads newspapers and advertisements the worries of unnecessary and imaginary troubles are there already, and one of the main duties of the school doctor is to ease the minds of children and parents, especially the latter, when there is nothing to worry about. I personally spend much more time in clinics telling anxious people that there is nothing to worry about than in telling them that something needs attention. Again, although it was pointed out earlier that most of the complaints diagnosed at the routine inspection were already known to the mother, that is only half the story, for the mother also wants to know what to do about it. Advice, as to what to do, whom to go and see, recommendations to specialists, prognosis and relieving of unnecessary anxiety, gives to the routine inspection its great usefulness. Finally, recognition and treatment of minor deviations from the normal to prevent disease at a later stage when possible, is the main justification for school medical work.

\section{Suggestions for Improvement}

The discrepancy in some findings from the results that would be expected suggest the following improvements:

1. Without doubt, the chief improvement would be an adequate history with some discreet leading questions. In view of the shortage of medical man-power, the time given to each child can hardly be increased; the solution is then to be found in a more comprehensive history sheet to be filled in by the parent at home before the examination. As the dislike of forms is widespread throughout the community, and embarrassing questions will be asked, the form should be prefaced with words to the effect: "It is not compulsory for you to fill in this form, but in the best interests of your child it is advisable for you to do so." An adequate questionnaire will require much thought to compile and will not be attempted here. It must recognize the limited ability of many parents to understand its import; and must, of course, be available for the doctor when he examines the child. Many of the replies will be valueless, but others will contain useful information, and it 
would be the helpful replies, even if few, that would make the questionnaire worth while.

2. To promote the discovery of psychological disturbances, some questions such as these should be in the history sheet: "Are you worried about your child's behaviour? Does he mix with other children normally? Has he any habits that trouble you ? Is he backward at school?" When the doctor sees the mother and child he will be able to decide if the case is worth proceeding with further. If so, the next step should be the visit to the child's home of a trained social worker attached to the local Child Guidance Clinic, and then, if necessary, reference to the clinic itself. This procedure might help to solve the doctor's problem when the mother complains in the five allotted minutes that her child has got "nerves, doctor ".

3. To find out cases of anaemia there should be facilities for the doctor, should he think fit, to refer any pale child to a laboratory for a blood examination.

Personal Experience also Suggests the Following:

1. In my opinion one of the main functions of the school doctor is to allay unnecessary anxieties and to try to stop useless self-medication. A questionnaire should refer specifically to constipation, with a view to the prevention of routine use of purgatives. Another question should be, "Do you regularly give your child medicines of any sort?"

2. It is probably unnecessary to do a urine examination and to record the blood pressure of every child. Facilities, however, should be available for the doctor who wishes to make use of them in any case.

3. A trained physiotherapist should visit each school, much as the dentist does to-day. He (or she) should have all the new entrants paraded, pick out those with postural defects, flat feet, etc., and supervise their future training, giving special advice to the physical training instructor for the mild cases, treating others in his clinic, and referring yet others to an orthopaedist.

4. It is questionable if it will be necessary to radiograph the chest of every child under 14 should mass-radiography become available. The school doctor, however, should have access to such a unit and its specialist opinion for any child that, in his opinion, requires it. The day has departed when the conscientious doctor believed that the placing of a stethoscope on the chest disclosed all that mattered. Parents dimly recognize this fact too, and so far from unnecessary examinations causing neurosis, many an anxious and pleading parent whose requests at present are refused because of insufficient or imaginary signs or symptoms in the child, would become satisfied if convinced by a radiograph. The general public does not yet recognize that pulmonary tuberculosis manifests itself in the chest of a child in a different way from that of an adult.

If the following considerations are taken into account, the work of the school medical officer will certainly be made easier:

1. In a hurried examination of five minutes, by the time the doctor has finished he has probably forgotten something that he has found out. To enable him to 
concentrate on what he is doing he should have clerical assistance to write down findings as he goes along. A doctor and a clerk can do the work of two doctors, surely a cheap price to pay for more effective use of medical man-power. The accuracy of the recording will increase tenfold.

2. When new schools are built, attention should be paid to rooms for medical inspection. Above all, the doctor should have a room where he can talk freely to a parent without knowing that there is a crowd waiting just behind a screen.

3. Every possible form of persuasion should be used to get the parent to attend the routine school medical inspection, such as national propaganda by the Ministry of Education.

School medical inspections, if to be of value, must be done by physicians experienced in school medical work; this statement may be considered trite, but it has been suggested that this work be carried out by general practitioners. If so, it should be carried out by practitioners who are specially interested and experienced in this sort of work. It is to be hoped that the revelations in this paper of the underestimation of certain conditions, for example foot deformities and ear disease, by the writer, will be taken as evidence that special training and experience is required in order that the school doctor, now a very lowly person in the medical hierarchy, may assume his proper place.

\section{SUMMARY}

1. The incidence is described of 150 major and minor conditions, or their history, in 2,500 normal schoolchildren during routine medical inspections.

2. It is described how some conditions such as anaemia, maladjustment, backwardness, may be under-estimated.

3. The disadvantages of routine inspections, such as the harm that might be done by insistence of minor abnormalities, is mentioned.

4. The advantages of the inspections are discussed.

5. Recommendations are made for increasing their value.

I wish to thank Dr. J. H. Weir, Medical Officer of Health for Ilford, for much helpful criticism and permission to quote from the Annual Report of the Medical Officer of Health. The opinions and suggestions in the paper must, however, be regarded as purely personal.

\section{REFERENCES}

Annual Report of the Medical Officer of Health, Ilford (1940).

Cram, E. B. (1943). Amer. J. Dis. Child., 65, 46.

"Epidemics in Schools." (1938). M.R.C. Report Ser., 227. London.

Glover, J. A., and Wilson, J. (1932). Brit. med. J., 2, 506.

Gordon, I. (1942). Ibid., 1, 357.

Paton, J. H. P. (1943). Quart. J. Med., N.S. $12,119$.

Schüffiner, W., and Swellengrebel, N. H. (1943). Zbl. Bakt., 1 Abt. Orig. 151, 71. Abstr. in Trop. Dis. Bull., 1945, 42, 922.

"Special Educational Treatment." (1946.) Min. Educ. Pamphlet No. 5, H.M.S.O.

Wilkins, E. H. (1940). Med. Off., 64, 157. (1941). Ibid., 66, 5. 